\title{
Coating of Silicate Glass Ceramics Containing Tricalcium Phosphate on Zirconia Ceramics
}

\author{
Masahiro Ashizuka and Eiichi Ishida \\ Department of Materials Science and Engineering, \\ Kyushu Institute of Technology, 1-1, Sensui-cho, Tobata-ku. \\ Kitakyushu 804-8550, JAPAN
}

(Received September 18,2000)

\begin{abstract}
A zirconia substrate was coated with silicate glass ceramics containing tricalcium phosphate. The zirconia substrate consists of tetragonal zirconia polycrystals containing $3 \mathrm{~mol} \% \mathrm{Y}_{2} \mathrm{O}_{3}$. Two types of silicate glass (Diop-TCP and Diop-An-TCP) were used as coating materials. Tricalcium phosphate (TCP) was added to the composition of diopside (Diop) and to the eutectic composition (Diop-An) of diopside and anorthite (An). Two types of glass (Diop and Diop-An) without TCP were used as reference coating materials. The silicate glass is crystallized in the coating process. The adhesion strength between the zirconia substrate and the coating layer was measured with a shear strength test. When Diop-TCP was used as the coating material, the optimum temperature was $1573 \mathrm{~K}$, and cracks appeared in both the zirconia substrate and the coating layer. The maximum adhesion strength was $46 \mathrm{MPa}$. The optimum temperature for coating by Diop-An-TCP was $1548 \mathrm{~K}$, and cracks did not appear in the zirconia, coating layer or interface. The maximum adhesion strength was 65 MPa. The diffusion layer penetrated by coating materials was in the zirconia substrate adjacent to the coating layer.
\end{abstract}

\section{INTRODUCTION}

Glass and glass-ceramics containing calcium phosphate have been of considerable interest for artificial biomaterials because calcium phosphates are the main component of bones and teeth $/ 1,2 /$.

Hench et al. have found that a $\mathrm{Na}_{2} \mathrm{O}-\mathrm{SiO}_{2}$ glass containing $\mathrm{CaO}$ and $\mathrm{P}_{2} \mathrm{O}_{5}$ bonded to bone tissue $13 /$. However, its strength was as low as $70 \mathrm{MPa}$. On the other hand, Kokubo et al. have reported that $\mathrm{CaO}-\mathrm{MgO}-$ $\mathrm{SiO}_{2}-\mathrm{P}_{2} \mathrm{O}_{5}$ glass ceramics precipitating wollastonite and hydoxyapatite (apatite) had a high strength of $213 \mathrm{MPa}$ 14-7/. The authors have been studying the mechanical properties of diopside or anorthite glass ceramics containing tricalcium phosphate, and have reported that these glass ceramics have a high strength of 215-228 $\mathrm{MPa} / 8,9 /$. However, the mechanical properties of bioactive ceramics such as apatite or glass ceramics containing hydoxyapatite or TCP are smaller than those of bioinert ceramics such as alumina. As a method to reinforce the low strength in bioactive ceramics, several researchers have coated the bioactive ceramics on highstrength ceramics $/ 10,11 /$.

Kawamoto et al. /10/ and Yokogawa et al. /11/ have reported the coating of tricalcium phosphate on zirconia substrates using magnesium metaphosphate as an insert material. On the other hand, we have already studied the joining of zirconia-to-zirconia using $\mathrm{CaO}-\mathrm{MgO}-\mathrm{SiO}_{2}-$ $\mathrm{Al}_{2} \mathrm{O}_{3}$ glass and discovered that this type of glass was a good insert material $/ 12 /$. The glass prepared by adding TCP to the insert materials used in the previous paper $/ 12 /$ is utilized as the coating material in this study.

The zirconia substrate consists of tetragonal zirconia polycrystals containing $3 \mathrm{~mol} \% \mathrm{Y}_{2} \mathrm{O}_{3}$. Four types of glass were used as coating materials. Two coating 
materials (Diop-TCP and Diop-An-TCP) were silicate glass with tricalcium phosphate (TCP) added to both the composition of diopside (Diop) and the eutectic composition (Diop-An) of diopside and anorthite (An). The two other coating materials did not contain TCP and were used as reference coating materials. The glass was crystallized during the coating process, that is, the coating glass material on the zirconia substrate was transformed into silicate glass ceramics.

\section{EXPERIMENTAL' PROCEDURE}

Zirconia powder was uniaxially pressed at $20 \mathrm{MPa}$ and then isostatically compacted at $150 \mathrm{MPa}$. The compacted specimens were sintered at $1773 \mathrm{~K}$ for two hours. The sintered zirconia specimens were discs of about $15 \mathrm{~mm}$ in diameter and $5 \mathrm{~mm}$ in thickness. The specimens were abraded using \#500 emery paper, and utilized as base substrates. The glass powders used as coating materials were from commercially available calcium carbonate, magnesium oxide, calcium phosphate dibasic and anhydrous silicate. These raw materials were mixed in a fixed ratio, then melted at $1723 \mathrm{~K}$ for one hour in a platinum crucible and finally quenched. The quenched glasses were ground using a ball mill to a diameter of less than $5 \mu \mathrm{m}$ for the coating material. Table 1 shows compositions and abbreviations of the coating materials used in this study. Specimens were prepared by placing glass powder on the zirconia substrates. The specimens were then heated at $0.16 \mathrm{~K} / \mathrm{s}$, and cooled after holding them for one hour at a coating temperature.

Table 1

Symbols for coating materials and compositions

\begin{tabular}{cc}
\hline Symbols & Composition / mass\%) \\
\hline Diop & 100 Diopside \\
Diop - TCP & 62 Diopside + 38 TCP \\
Diop - An & 58 Diopside +42 Anorthite \\
Diop - An - TCP & 58 (62 Diopside + 38 TCP) \\
& +42 (68Anorthite + 32 TCP) \\
\hline
\end{tabular}

Diop : Diopside ( $\left.\mathrm{CaO} \mathrm{MgO} \cdot 2 \mathrm{SiO}_{2}\right)$

An : Anorthite $\left(\mathrm{CaO} \cdot \mathrm{Al}_{2} \mathrm{O}_{3} \cdot 2 \mathrm{SiO} 2\right)$

TCP : Tricalcium phosphate (3CaO-Pís)
The precipitated crystallite in the coating layer was identified by $\mathrm{X}$-ray diffraction. The microstructure in the vicinity of the interface between the zirconia substrate and the coating material was observed with scanning electron microscopy (SEM), and composition and characteristic $\mathrm{X}$-ray images were obtained. The line analyses of several elements in a perpendicular direction to the interface were carried out with a electron probe microanalyser (EPMA), and the distribution of elements was compared with the SEM results.

The adhesion strength between the zirconia substrate and the coating layer was evaluated by using the specimens that glass powder was inserted between two zirconia disks. The specimens had been heated at the same temperatures as those during coating. The adhesion strength was evaluated by a shear strength test (crosshead speed: $8.3 \mu \mathrm{m} / \mathrm{s}$ ).

\section{RESULTS AND DISCUSSION}

\subsection{Adhesion strength}

Figure 1 shows the adhesion strength for four kinds of coating materials. When only Diop was used as the coating material, the most suitable coating temperature was high at $1623 \mathrm{~K}$ and the maximum adhesion strength was as low as $22 \mathrm{MPa}$. The destruction in this case happened in the coating layer. The most suitable coating temperature fell to $1573 \mathrm{~K}$ in Diop-TCP when TCP was added to Diop, and the greatest adhesion strength rose to $46 \mathrm{MPa}$. The destruction path in this case showed a mixing mode through the coating layer and the interface of the zirconia substrate / coating layer. When Diop-An was used as the coating material, the strength rose to 73 $\mathrm{MPa}$ at the coating temperature of $1548 \mathrm{~K}$. This value is a maximum adhesion strength measured in this study, but the coating temperature range to show the high strength was very narrow. In Diop-An-TCP with TCP added to the eutectic composition glass (Diop-An) of diopside and anorthite, the greatest strength was at 1548 $\mathrm{K}$ and fell to $65 \mathrm{MPa}$ lower than Diop-An, but the coating temperature range to show the high strength slightly became large. When Diop-An and Diop-AnTCP were used as coating materials, the zirconia substrate / coating layer showed destruction inside the coating layer. 


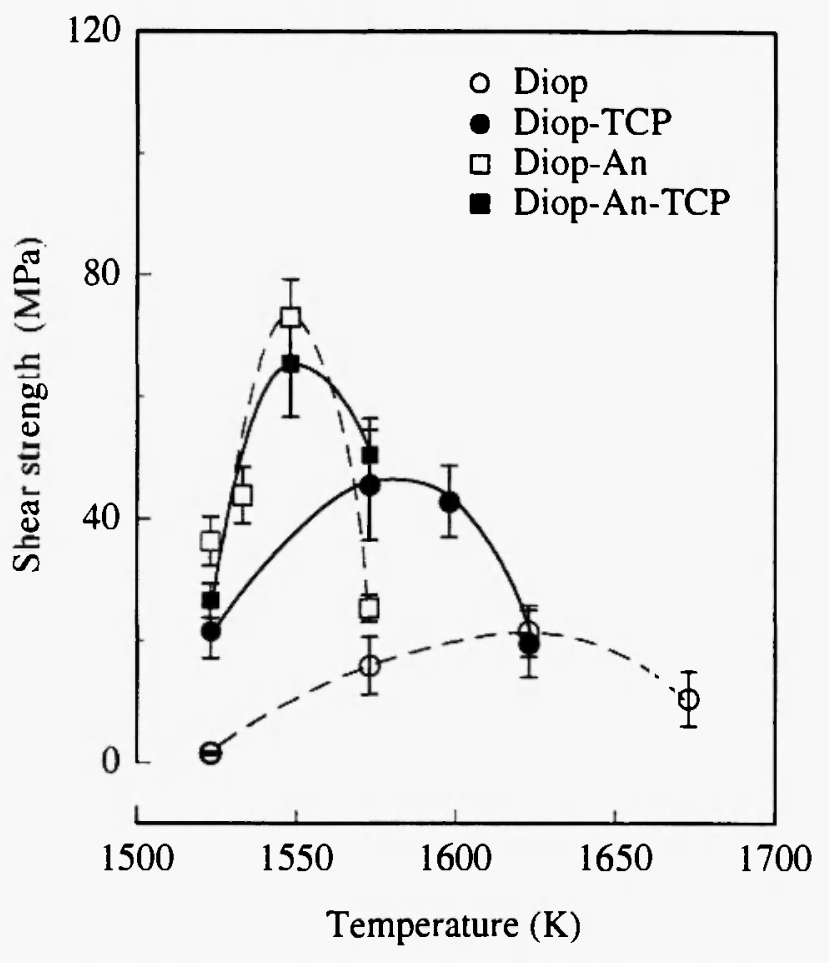

Fig. 1: Adhesion strength between zirconia substrates and several types of glass used as coating materials.

\subsection{Precipitated crystallite in the coating layer}

Zirconia substrates were coated with four kinds of glass powders, and crystalline phases precipitating in the coating layer at a fixed temperature were identified by $\mathrm{X}$-ray diffraction. Figure 2 shows the $\mathrm{X}$-ray diffraction patterns of coating layers fabricated by using Diop-TCP, Diop-An and Diop-An-TCP except for Diop as coating materials. Most of the Diop-coating layers heated at $1673 \mathrm{~K}$ were amorphous and small amounts of diopside crystallite were observed. If the Diop-TCP was used as the coating material, only $\beta$-TCP precipitated at $1573 \mathrm{~K}$, and one part of the TCP changed into apatite at $1598 \mathrm{~K}$ with diopside precipitation. On the other hand, if the Diop-An was used as the coating layer, the coating phase was amorphous at both $1548 \mathrm{~K}$ and $1573 \mathrm{~K}$. Furthermore, when Diop-An-TCP was the coating layer, $\beta$-TCP, and small amounts of apatite, diopside and anorthite were precipitated at $1548 \mathrm{~K}$. The anorthite, the diopside and the apatite remarkably precipitated at 1573 $\mathrm{K}$.

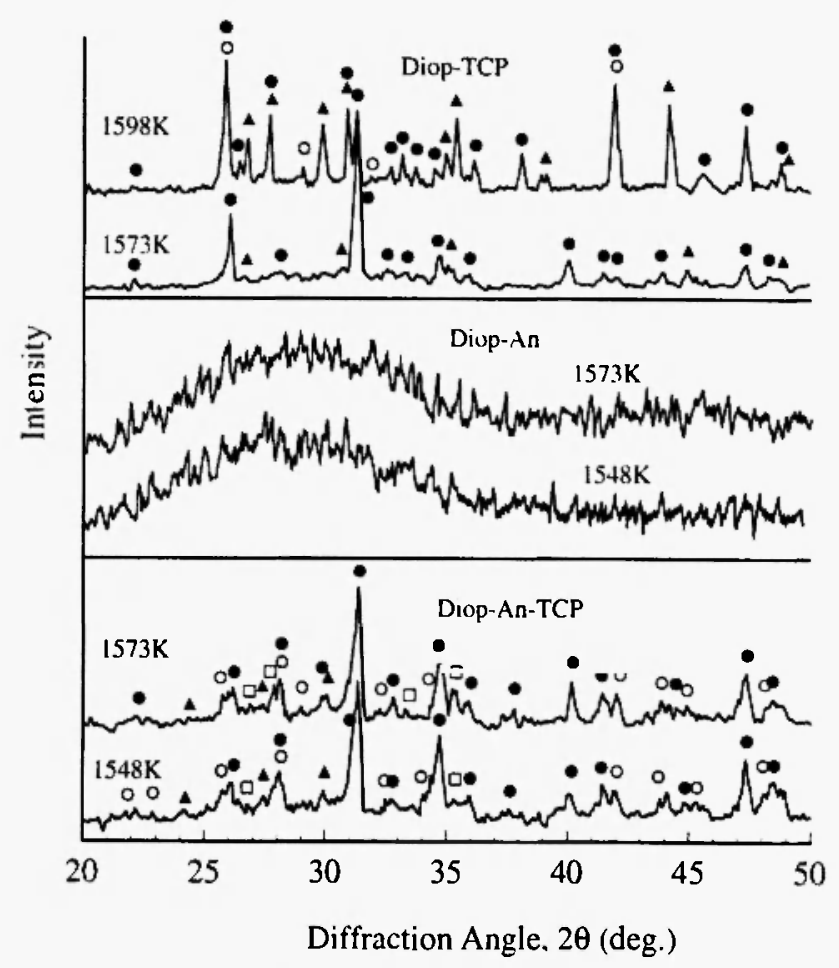

Fig. 2: $X$-ray diffraction patterns of coating layers. - $\beta$-TCP, O Apatite, $\Delta$ Diopside, $\square$ Anorthite

\subsection{Observation of adhesion interface}

After the precipitated crystallite was identified, the bonding interface of the specimen was cut off in a direction perpendicular to the interface. The microstructure in the vicinity of the bonding interface was observed by using SEM, the composition image and the characteristic X-ray image. Figures 3, 6 and 7 show the results. Furthermore, EPMA line-analyses of elements are shown in Figures 4, 5, 8 and 9.

Although we did not show in this study when the Diop was used as the coating material at $1673 \mathrm{~K}$, a large diffusion layer of about $800 \mu \mathrm{m}$ was made in the zirconia substrate side; there was also a big crack parallel to the bonding interface in the diffusion layer. However, even if the big crack occurred in the diffusion layer of the zirconia substrate, the fracture was generated in the coating layer.

Figure 3 shows the SEM photographs (A), the composition images $(\mathrm{B})$, and the characteristic $\mathrm{X}$-ray image (C) of $\mathrm{Ca}, \mathrm{Mg}, \mathrm{Si}, \mathrm{P}$ and $\mathrm{Zr}$ in both the zirconia substrate and coating layer in the vicinity of the bonding 


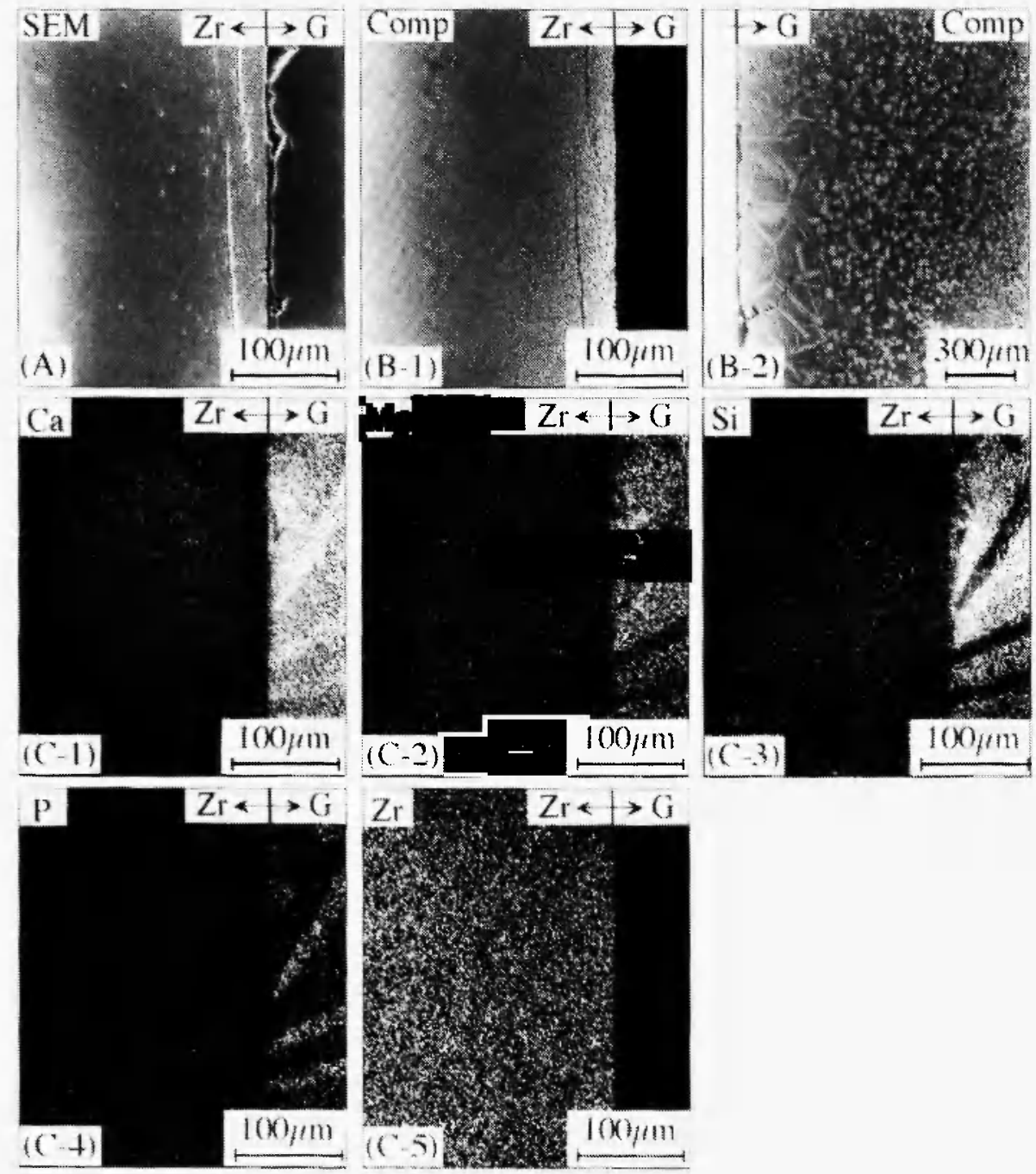

Fig. 3: SEM image (A), compositional image (B-1 and B-2) and characteristic X-ray image (C-1 to C-5) in vicinity of interface formed by Diop-TCP glass at $1573 \mathrm{~K}$. Symbols $\mathrm{Zr}$ and $\mathrm{G}$ accompanying arrow in figure show zirconia substrate and coating glass (coating material), respectively.

interface in the specimen coated with the Diop-TCP at $1573 \mathrm{~K}$. The diffusion layer of zirconia substrate side was $150 \mu \mathrm{m}$, and $\mathrm{Ca}, \mathrm{Mg}, \mathrm{Si}$ penetration was recognized. On the other hand, a rod-like crystallite existed in the coating layer adjacent to the zirconia substrate, and a grown granular crystallite was recognized at a location distant from the bonding interface. In this case, cracks occurred in both the zirconia substrate and the coating layer, and a part of the interface layer between the zirconia substrate and the coating layer was easily exfoliated during grinding.
When the coating temperature rose to $1598 \mathrm{~K}$, the crack became big.

Figure 4 shows the EPMA line-analysis of elements in the vicinity of the bonding interface of the zirconia substrate / coating layer (Diop-TCP). A steep change in the composition ratio exists in the coating layer, and it corresponds to the rod-like crystalline precipitation shown in Figure 3. The concentrations of $\mathrm{Ca}$ and $\mathrm{P}$ became high in the region where the composition ratio suddenly changed. On the other hand, the concentration of $\mathrm{Mg}$ and $\mathrm{Si}$ became low. This result and the 


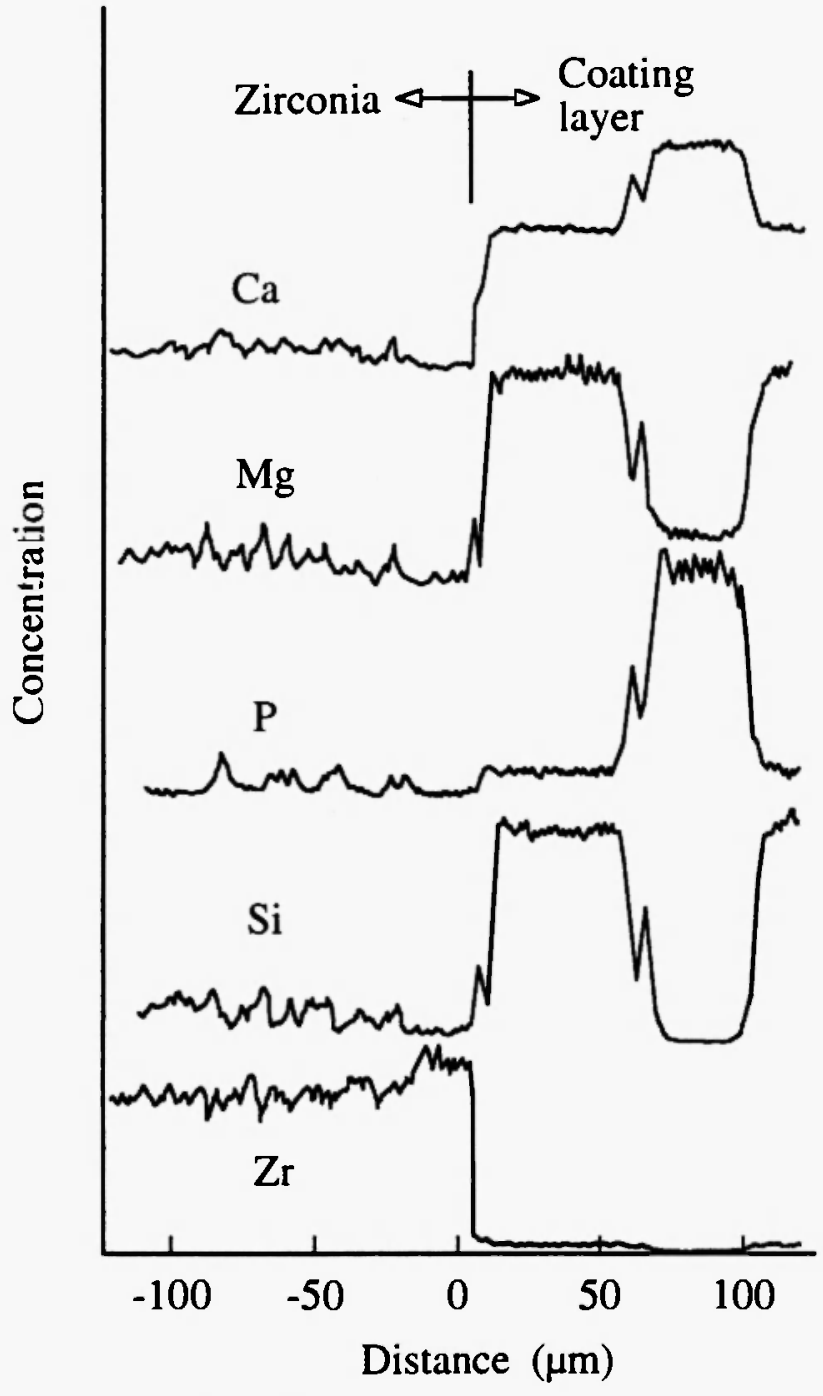

Fig. 4: EPMA line analyses for concentration distribution of several elements in vicinity of interface in zirconia substrate / coating layer (Diop-TCP).

identification of the precipitation crystallite by X-ray diffraction indicates that the rod-like precipitation crystallite is tricalcium phosphate.

Figure 5 shows results magnified about five times in the vertical axis direction of Figure 4 for a detailed concentration distribution of the diffusion layer in the zirconia substrate measured by EPMA. The concentrations of $\mathrm{Ca}, \mathrm{Mg}$ and $\mathrm{Si}$ became high in the diffusion layer of the zirconia substrate, and the $P$ concentration was small. Therefore, we assumed that the diffusion layer was made by the penetration of some

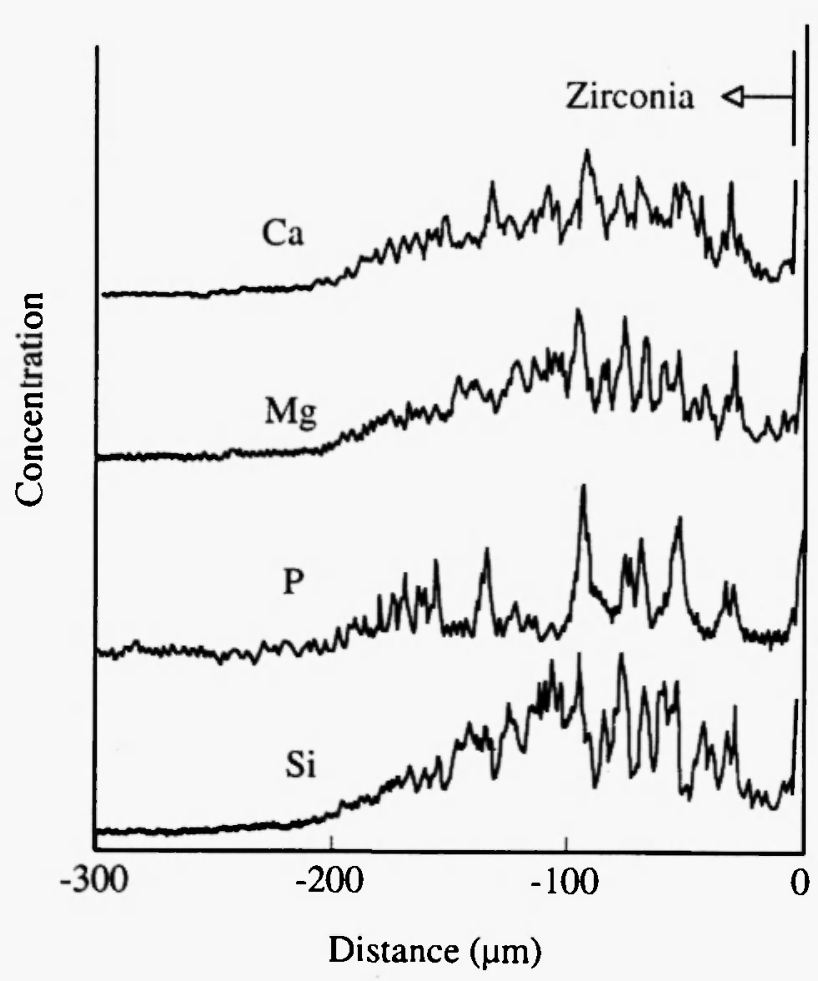

Fig. 5: EPMA line analyses for concentration distribution of several elements in the zirconia substrate (vertical axis is extended about 5 times larger than that in Fig 4).

components in the coating materials.

Figure 6 shows the SEM (A) and the composition image (B) in the vicinity of the interface between the zirconia substrate and the coating layer when the Diop-
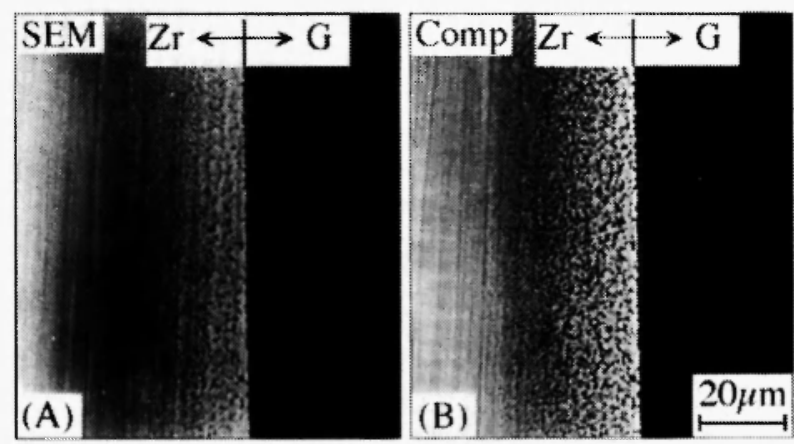

Fig. 6: SEM image (A) and compositional image (B) in vicinity of interface formed by Diop-An at $1548 \mathrm{~K}$. Symbols $\mathrm{Zr}$ and $\mathrm{G}$ accompanying arrow in figure show zirconia substrate and coating glass (coating material), respectively. 
An glass was used as the coating material at $1548 \mathrm{~K}$. There was a diffusion layer of about $30 \mu \mathrm{m}$ in the zirconia substrate. The diffusion layer grew to about 50 $\mu \mathrm{m}$ when the temperature rose to $1573 \mathrm{~K}$. Although the result of the EPMA line analyses for the Diop-An coating material is not shown in this paper, the amounts of $\mathrm{Ca}, \mathrm{Mg}, \mathrm{Si}$ and $\mathrm{Al}$ in the diffusion layer were slight in comparison with those in the Diop-TCP. Furthermore, the concentration ratio of these components resembled that in the coating layer, that is, the fluctuation of components was scarcely recognized in both the zirconia substrate and the coating layer. This phenomenon corresponds to the identification that the coating layer is amorphous. Cracks were not observed in the zirconia substrate, the coating layer or the interface, and the adhesion strength in the zirconia substrate / coating layer was large. From Figure 1, we estimate that the high adhesive strength in the Diop-An occurs because cracks are not recognized in any place, adhesion is good, the diffusion layer is thin, and the amount of the penetrated glass component is slight.

Figure 7 shows the SEM photographs (A), the composition images (B) and the characteristic X-ray images $(\mathrm{C}$ ) of $\mathrm{Ca}, \mathrm{Mg}, \mathrm{Al}, \mathrm{Si}, \mathrm{P}$ and $\mathrm{Zr}$ in the interface
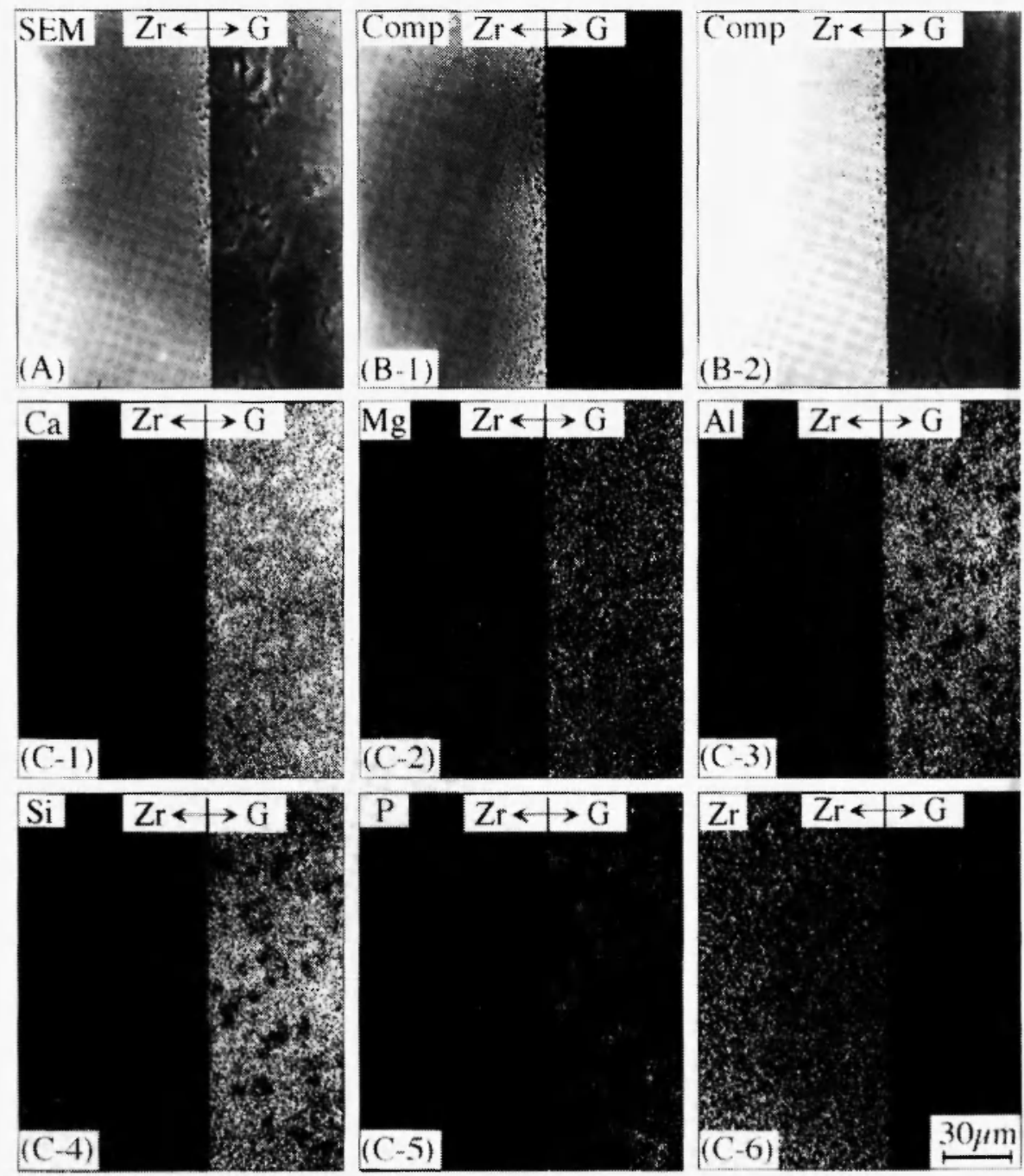

Fig. 7 SEM image (A), compositional image (B-1 and B-2) and characteristic X-ray image (C-1 to C-6) in vicinity of interface formed by Diop-An-TCP glass at $1548 \mathrm{~K}$. Symbols $\mathrm{Zr}$ and $\mathrm{G}$ accompanying arrow in figure show zirconia and coating glass (coating material), respectively. 
vicinity of the zirconia substrate / coating layer using Diop-An-TCP as the coating material at $1548 \mathrm{~K}$. The adhesion of the coating material in this system was good, which is similar to the Diop-An system, and the thickness of the diffusion layer in the zirconia substrate was $30-40 \mu \mathrm{m}$ at the coating temperature of $1548 \mathrm{~K}$ and 60-70 $\mu \mathrm{m}$ at $1573 \mathrm{~K}$. A granular crystallite also precipitated in the coating layer. However, the size of the granular crystallite was smaller than that in DiopTCP. Voids were recognized in the coating layer about $40 \mu \mathrm{m}$ away from the interface in the SEM photograph shown in Figure 7 (A). However, we suppose that the voids originated from the exfoliation of the precipitated crystallite during grinding

Figure 8 shows the EPMA line analysis in the interface vicinity of the specimens using Diop-An-TCP. The fluctuation of these components corresponds to the existence of precipitated phases in the coating layer shown in Figure 7. This result suggests the tricalcium phosphate crystallite precipitates when concentrations of $\mathrm{Ca}$ and $\mathrm{P}$ are high and the concentrations of $\mathrm{Mg}, \mathrm{Al}$ and $\mathrm{Si}$ are low in the place where the fluctuation of the components is generated. The crystallite was identified by the X-ray diffraction of the coating layer as tricalcium phosphate.

Figure 9 shows the EPMA line analysis of the diffusion layer in the zirconia substrate enlarged about 8 times for the vertical direction (concentration axis) of Figure 8. The concentrations of $\mathrm{Ca}, \mathrm{Mg}, \mathrm{Si}$ and $\mathrm{Al}$ became high in the diffusion layer in the zirconia substrate. On the other hand, the $P$ concentration was small. There was a small amount of the glass component penetrating the diffusion layer compared with that in Diop-TCP.

For example, when Diop-An-TCP system was used as the coating material, the adhesion strength was higher than that in Diop-TCP, but lower than that in Diop-An. Furthermore, the diffusion layer in the zirconia substrate became thinner and the amount of the penetrating glass component was smaller. We suppose that the strength became lower than that of the Diop-An system because the precipitation crystallite in the coating layer was the weaker TCP in spite of the good bonding situation.

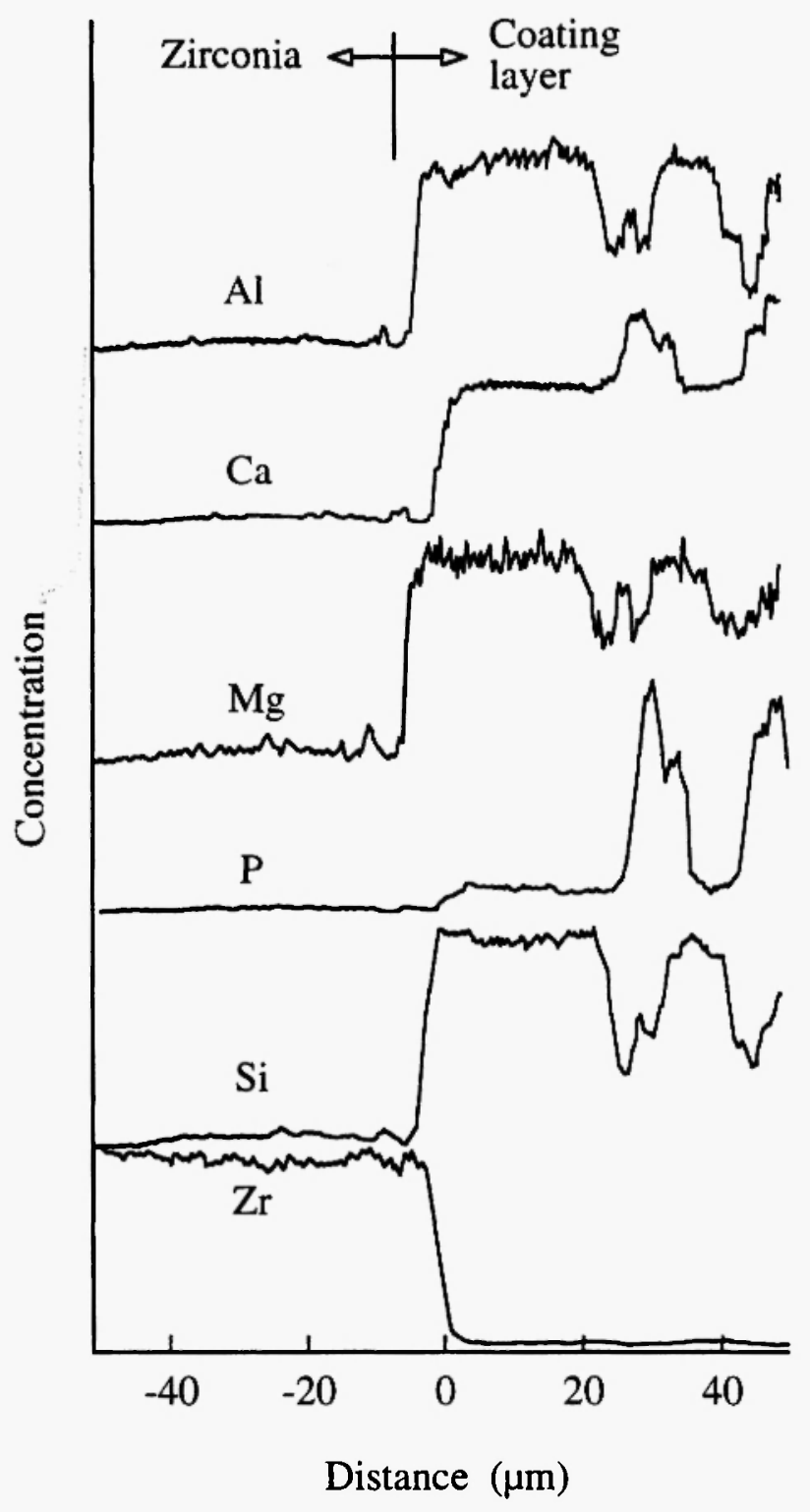

Fig. 8: EPMA line analyses for concentration distribution of several elements in vicinity of interface in zirconia substrate/coating layer (Diop-An-TCP).

\section{SUMMARY}

We measured the adhesion strength between the $\mathrm{ZrO}_{2}$ substrate and the coating layer fabricated with silicate glass (Diop-TCP, Diop-An-TCP). TCP was 


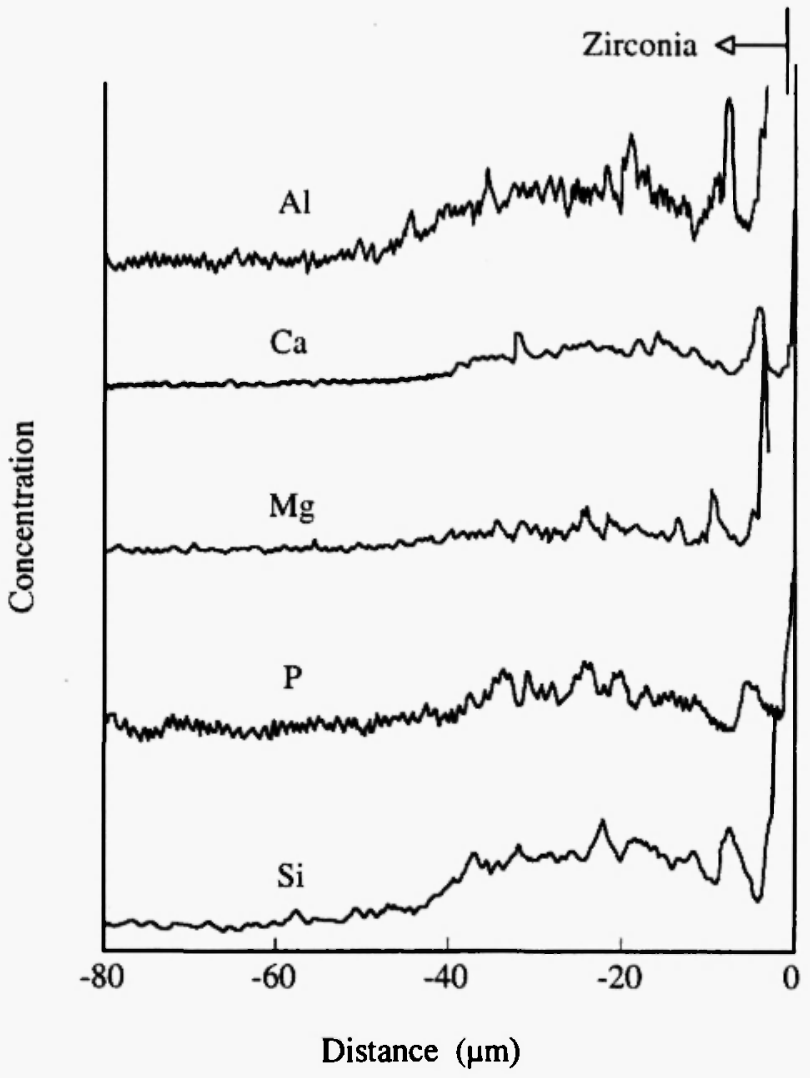

Fig. 9: EPMA line analyses for concentration distribution of several elements in zirconia substrate (vertical axis is extended about 8 times larger than that in Fig 8).

added to diopside (Diop) and to the eutectic composition (Diop-An) of diopside and anorthite (An). We observed the microstructure and the distribution profiles of elements in the interface vicinity of the zirconia substrate and the coating layer, and the formation of cracks. When Diop-TCP was used as the coating material, the most suitable coating temperature was $1573 \mathrm{~K}$, and the greatest adhesion strength was 46 $\mathrm{MPa}$. We recognized cracks in both the zirconia substrate and the coating layer. When Diop-An-TCP was used as the coating material, the most suitable coating temperature was $1548 \mathrm{~K}$, and the greatest adhesion strength was $65 \mathrm{MPa}$. No crack appeared in any place of the zirconia substrate, the coating layer or the interface. There was good adhesion. We recognized the diffusion layer showing the penetration of the coating material in the zirconia substrate adjacent to the coating layer. When Diop-An-TCP was used as the coating material, the diffusion layer was thin and the amount of penetrating components was slight. Although the good adhesion was obtained in Diop-An-TCP, the temperature range showing high adhesion was narrow.

\section{REFERENCES}

1. L.L. Hench, J. Amer. Ceram. Soc., 98, 1705 (1998).

2. M. Akao, N. Miura and H. Aoki, Yogyo-KyokaiShi, 92, 672 (1984).

3. L.L. Hench, R.J. Splinter, W.C. Allen and T.K. Greenlee, Jr., J. Biomed. Mater. Res. Symp., No. 2, Part 1, 117 (1971).

4. T. Kokubo, R. Nagasima and J. Tashiro, YogyoKyokai-Shi, 90, 151 (1982).

5. T. Kokubo, S. Ito, M. Shigematsu, S. Sakka and Y. Yamamuro, J. Mater. Sci, 20, 2001 (1985).

6. T. Kokubo, S. Ito, S. Sakka and Y. Yamamuro, J. Mater.Sci., 21, 536 (1986).

7. T. Kokubo, S. Ito, M. Shigematsu, S. Sakka and Y. Yamamuro, J. Mater. Sci., 22, 4067 (1987).

8. M. Ashizuka, M. Nakatsu and H. Ishida, J. Ceram. Soc. Japan, 98, 204 (1990).

9. M. Ashizuka and E. Ishida, J. Mater. Sci., 104, 345 (1996).

10. Y. Kawamoto, Y. Yokokawa, M. Karasuyama, S. Kawamura and T. Suzuki, J. Ceram. Soc. Japan, 99, 19 (1991).

11. Y. Yokokawa, Y. Kawamoto, M. Karasuyama, T. Suzuki and S. Kawamura, J. Ceram. Soc. Japan, 99, 211 (1991).

12. M. Ashizuka and H. Ishida, J. Ceram. Soc. Japan, 104, 204 (1996). 